\title{
A presença indígena na universidade
}

Ailton Krenak

O debate acerca da presença indígena na universidade vem sendo feito em diversas ocasiões nos últimos anos, especialmente ressaltando as dificuldades relacionadas à permanência, a partir do acesso por meio de cotas, que gradualmente vão sendo implantadas por nossas universidades públicas no Brasil. Aqui na UNICAMP teremos, neste ano, o primeiro vestibular indígena ${ }^{1}$, levando à frente este debate que precisa ser aprofundado. Assim, cumprimento alguns de vocês que já estão há mais tempo engajados com a questão indígena na universidade, também com a presença indígena no contexto das nossas sociedades, os povos indígenas na sociedade brasileira, num contexto mais amplo.

Estou muito admirado de fazer este debate aqui em São Paulo, na UNICAMP, porque para mim é São Paulo. Eu olho esse lugar da perspectiva de quem formou a sua visão sobre o Brasil, sobre a nossa realidade mais regional, de um outro lugar que são aquelas regiões de serra, que nós identificamos como Minas Gerais, como um território de muitos povos, mas que desde o final da colonização foi se configurando como aquele imenso garimpo mineiro, onde os povos indígenas nem sempre comungam a mesma identidade dos garimpeiros que historicamente nós combatemos, porque são esses camaradas que decidiram que nossa mãe-terra pode ser esquadrinhada, transformada em mercadoria e vendida no mercado como uma commodity. Isso é uma velha prática mineira que me incomoda muito, porque, se há trezentos anos aquela comunidade mineira precisava de uma economia extrativista garimpeira pra poder criar alguma riqueza, me admira que trezentos anos depois, sendo uma das regiões do Brasil que fundou uma das primeiras universidades - lá tem uma grande escola de engenharia de minas, tem a escola de farmácia, parece que é uma das mais antigas do Brasil -, no entanto, com todo esse desenvolvimento, digamos assim, de saberes, eles não conseguiram ainda sair de uma economia extrativista que exaure o nosso território e que põe em risco a vida de muitos seres, não só os humanos, mas de muitos outros seres, de muitos outros organismos, formas de vida.

1 Ailton Krenak, nesta ocasião, compôs a mesa-redonda A presença indígena na universidade, realizada no auditório do Instituto de Economia da Universidade Estadual de Campinas (UNICAMP) no dia 28 de novembro de 2017. 
Creio que alguns de vocês tiveram notícia de um grave crime ambiental que abateu a bacia do Rio Doce, que é o rio onde eu nasci. Eu nasci na margem do Rio Doce, um rio que está temporariamente em coma, por uma atividade econômica insana e irresponsável que qualquer um de nós poderia prever, uma atividade econômica daquela, feita durante muito tempo, sem nenhum cuidado, podia dar num desastre e deu. $O$ desastre foi plasmar $650 \mathrm{~km}$ da bacia do rio que nós tivemos sempre como uma guia para nossa existência, para nossa vida, plasmado por uma lama tóxica que deixa esse rio temporariamente fora do nosso alcance. $\mathrm{O}$ rio teve que buscar um lugar do seu lençol freático e se refugiar abaixo das lajes de pedra que fazem a sua calha, por onde ele corria, e buscar um lugar oculto nas galerias abaixo da calha, naquilo que talvez esteja abaixo ainda do nosso lençol freático, para ele continuar existindo como uma entidade, porque, como um organismo que nós pudéssemos tocar, o Watú, que é como nós chamamos o Rio Doce, ele está temporariamente fora do nosso alcance.

É uma experiência arrebatadora você experimentar a perda de um ente tão transcendente para sua memória, para o seu sentido de viver, para aquilo que para alguns de nós significa a nossa relação com o que é transcendente, com aquilo que é do espírito, que é da nossa transcendência e não somente da nossa subsistência. O rio não é só um suprimento para nossa pesca, água, agricultura, irrigação ou qualquer outra atividade relacionada com a produção e reprodução, mas ele é também o elemento da nossa memória sobre quem nós somos. Ele reafirma a nossa identidade, ele integra uma territorialidade além do material, ele tem um componente subjetivo essencial para constituir as nossas identidades, ele é o nosso outro, o Watú é o outro que nós chamamos de nosso avô, então nosso avô foi posto em coma, por um saque econômico irresponsável e que se justifica com a ideia de promover o nosso desenvolvimento.

O meu comentário acerca desse lugar de onde eu venho é pra informar um pouco também do meu estado de espírito com relação ao entorno dessa região de Minas Gerais, que de certa maneira é vizinha também desse outro estado que é São Paulo e dessas configurações que nós fazemos desse território Brasil, onde as políticas hoje, geopolíticas, vão definindo prioridades para cada um desses territórios e essas prioridades afetam a nossa vida diretamente. Às vezes, nós não percebemos o quanto essas prioridades, que são eleitas para cada uma das nossas regiões, afetam hoje a nossa vida e não atinamos também como irão afetar a vida dos nossos filhos, dos nossos netos, das gerações futuras. Nós estamos, de certa maneira, liquidando um patrimônio comum hoje e criando uma dívida para o futuro. Essa localização do lugar onde o povo Krenak historicamente viveu fica na região de floresta do Rio Doce, que de floresta não tem mais nem amostra, porque a única formação florestal que tem lá é eucalipto, desde quando as empresas florestais tomaram aquela região como um verdadeiro jardim para o plantio de árvores comerciais. Assolaram a nossa paisagem com essa árvore monótona, o eucalipto, e se associaram com a atividade da mineração e a siderurgia. O monocultivo de floresta plantada é um desrespeito histórico pela presença de outros modos de viver naquele lugar que, no caso, trata-se do modo de vida do povo Krenak, que na literatura vocês devem encontrar com apelidos. Um dos apelidos que vocês vão encontrar na 
literatura, inclusive mais recente, onde nós somos chamados de Botocudos - que é só um acúmulo de ofensas, pois, por não nos conhecerem, sempre nos chamaram por apelidos e por nomes com forte significado pejorativo.

Vocês estão experimentando essa passagem pela experiência da formação numa comunidade de aprendizagem que é a universidade, mas eu não consigo distinguir muito esse lugar da universidade dos outros lugares, onde outras comunidades de saberes se constituem, onde, em outros lugares não demarcados com esse sinal, digamos assim, da educação, da educação formal, que comunidades coletivas inteiras experimentam uma criativa formação de pessoas, formando pessoas, não Fernando Pessoa - que a gente pode homenagear aqui no nosso encontro, o querido Fernando Pessoa -, mas formando pessoas que, quem dera, pudessem ser verdadeiras "pessoas". Nesse sentido, pudessem transcender o sentido objetivo, prático, metódico, por uma vida poética, que afeta os sentidos da vida, que dá sentido à existência e que não nos enquadra como as instituições consideradas educadoras têm feito historicamente; o serviço de empacotamento da criação para nos transformar em sujeitos produtivos, vinculados a um complexo sistema de produção que não leva em conta que a terra é um organismo vivo, é a nossa mãe, e que talvez por esse vínculo de maternidade que nós podemos estabelecer com a terra nos permitisse uma janela de aprendizado onde nós tomássemos a terra como nossa principal mestre; a terra como nossa curadora e orientadora, que nos propiciasse um guia geral para a vida. E a nossa especialização de nos tornarmos arquitetos, engenheiros, médicos, biólogos, astronautas, que ela fosse uma parte da nossa experiência estendida de seres humanos criativos, mas que privilegiadamente aprende com seu ambiente, aprende com seu habitat, aprende com uma ecologia profunda, uma ecologia que integra seres humanos a ponto de eles não distinguirem mais natureza e cultura, ao ponto de se confundir o que acontece com um rio, com uma montanha e com seu próprio povo, a ponto das pessoas poderem se afetar quando uma montanha é cortada, quando uma árvore é degolada ou quando um rio é infectado, como o Rio Tietê, o Pinheiros, e uma centena de rios podres que nós temos espalhados por aí, como um atestado da nossa competência, da nossa capacidade de produção, de transformação da natureza em esgoto.

Nós temos constantemente encontrado exemplos da nossa capacidade de transformar a natureza em algo pior do que ela é. Não conheço nenhuma experiência em que nós abordamos qualquer aspecto da natureza, seja no campo das ciências naturais, seja no campo da engenharia, da biologia, em que nós tocamos a natureza e constatamos cem anos depois que ela tenha ficado melhor. Eu gostaria que vocês conhecessem algum exemplo, em algum lugar do mundo, de onde uma incrível civilização criativa tenha metido a mão e transformado a natureza em alguma coisa melhor do que ela fosse na sua origem. Se nós não podemos transformar a natureza em alguma coisa melhor do que ela já é, nós deveríamos tocar a natureza com necessário respeito e cuidado para que a gente pudesse só nos integrar com os ciclos da natureza e não depredar as paisagens por onde nós passamos, seja floresta, seja um rio, um deserto. 
O deserto é cheio de vida, pleno de diversidade, de biodiversidade, de complexidade, como uma floresta. Nós é que elegemos algumas paisagens culturalmente que nós queremos cultivar e algumas paisagens que nós, por alguma razão na nossa formação, achamos que elas são desprezíveis, são inúteis e podem até ser deletadas do planeta porque não fariam falta. Eu sei que em muitos de nós existe o contágio da ideia de que o pior lugar do mundo seria o deserto. Alguns de nós seríamos incapazes de sobreviver nesse ambiente. O nosso sentido de utilidade das coisas nos faz desprezar a paisagem desértica por desconhecer a sua riqueza, mas nós podemos encontrar testemunhos de povos que nele viveram por gerações e gerações, que construíram e que constituíram culturas e experiências e aventuras maravilhosas de cultura e de seres humanos num lugar de deserto, civilizações. Isso deve chamar a nossa atenção sobre como nós elegemos algumas paisagens para existir e algumas para desaparecer. Parece que uma das paisagens que a cultura do ocidente, que se implantou aqui nas Américas, decidiu que era uma para desaparecer são as florestas. Se vocês olharem, na maioria das histórias de formação dos meninos brancos, dos meninos filhos dos europeus, a floresta é o lugar do lobo, é o lugar onde tem bicho, onde tem barbárie, onde tem perigo. Ora, se a floresta é um lugar tão apavorante, vamos deitar o machado nela, meter a motosserra, sentar fogo nela e transformá-la em qualquer outra coisa, por exemplo, em papel, celulose, estacas, assoalho, poste, vamos transformar isso em dinheiro, em suma, vamos fazer uma grana.

No caso da história do Brasil, fazer uma grana com a floresta foi a primeira coisa que os portugueses queriam fazer, gostaram de fazer, quando eles deram o nome para esse lugar de Brasil. Nós somos um país que tem o nome de madeira, tem o nome de uma árvore, Brasil. Parece que o nosso destino é acabar até com a última árvore enquanto ela estiver nos assombrando - ou dando sombra - com a ideia de uma floresta onde só tem sinais assustadores, porque, afinal de contas, índio e floresta são duas coisas que se misturam no imaginário das pessoas. Se a mata gelada da Europa tem ursos e lobos, na floresta tropical tem índios, e se nela há índios e é lugar tão inóspito, que os índios fiquem por lá.

Nossa universidade paralisada em si mesma demorou muito para entender, não como uma concessão, mas como uma obrigação histórica, que deve, sim, inserir todos nós, todo mundo, toda essa gente que se constitui nesse Brasil, nos seus espaços de circulação. Mas a marca da diferença persiste quando a gente trabalha a ideia dessa inserção num sistema de cotas, num sistema modulado, num sistema regulado. Eu nem estou botando em questão o princípio geral da ideia de instituições como a universidade ser ou não útil à trajetória dos povos indígenas aqui desse continente, porque um dia, antes mesmo de fazer esse comentário geral sobre a nossa complexa formação de sociedade que é o Brasil, eu podia simplesmente comunicar a vocês a minha ideia acerca de índios na universidade ou presença indígena na universidade, não relacionando isso, propriamente, com a presença indígena na nossa sociedade, porque os comentários que eu estou fazendo agora, eles dizem muito mais respeito à presença dos povos indígenas na sociedade brasileira, que é uma coisa tão mal resolvida quanto a presença indígena na universidade brasileira. 
Tem um ditado que diz que o cavaco não voa longe do pau, é um provérbio regional. E em primeiro lugar precisa ter uma lenha para você sentar o machado nela e voar um cavaco em algum lugar, mas o pedaço realmente fica na órbita da árvore que foi derrubada, e se a universidade reproduz o pensamento racista, preconceituoso, discriminatório, classificatório que tem na nossa sociedade brasileira, é claro que aqui dentro da universidade esses organismos estranhos vão também sofrer um período de, digamos, adaptação ao meio, porque não são daqui, mas estão se inserindo nesse contexto. Isso tem muito a ver com a história recente do Brasil, a história recente que eu digo aqui é uma história dos últimos cinquenta anos, porque se você recuar além dos cinquenta anos, a estratégia do Estado brasileiro era extinguir essa diferença, que é marcada com a presença dos povos indígenas na sociedade brasileira. Extinguir, mesmo quando ainda não era integrante do nosso vocabulário a palavra "genocídio", a nossa prática genocida já estava inserida no nosso contexto cultural de uma maneira naturalizada.

Mesmo mestres que construíram obras clássicas e admiráveis como o professor Darcy Ribeiro, por exemplo, se você pegar Os índios e a civilização e olhar aquelas pranchas onde são listados os povos em extinção ou desaparecidos no século XX, você vai observar certa naturalização do desaparecimento dos índios do arranjo da sociedade brasileira. É como se historicamente a gente tivesse um tempo para nos fundir com essa coisa do Brasil ao ponto de a gente desaparecer nessa diluição como diferença, diferença de língua, diferença de modos de ver o mundo, de cosmovisões, de percepções do estado de estar no mundo, o jeito de estar no mundo, não só uma caracterização como a pintura de urucum ou de jenipapo ou com o cocar, mas como modo de estar no mundo que talvez pudesse ser informado pela ideia de que nós aprendemos com a terra. Se nós aprendemos com a terra e vivemos essa integralidade da experiência humana com a terra, nós não vamos ficar sentindo que está faltando alguma coisa na gente.

No pensamento, na ontologia do colono, uma criança nasce vazia, a cabeça de uma criança é como uma cuia, um coité vazio e o papel do mundo adulto é encher esse coité de significados, encher essa cuia de significados. No pensamento de muitos desses povos que nós estamos, com licença, chamando de indígenas, que é um apelido, quando uma pessoa nasce, antes até de uma pessoa constituir-se pessoa, ele ou ela é uma construção, ele ou ela é um desejo, ele é uma expectativa cheia de existência, cheia de potência, é a potência da vida se expressando nos ciclos da nossa reprodução cultural, física, nas nossas famílias, naquilo que nós poderíamos chamar de constituir as nossas unidades que são comunidades, que são povos. Essas constelações de pessoas são constelações que têm uma vinculação cósmica. Para alguns de vocês que tem o seu pensamento educado pela racionalidade, pode parecer que eu estou fazendo um comentário místico sobre a experiência humana, sobre os ciclos de reprodução, nascer-morrer, que seja, mas eu estou falando de um jeito de estar no mundo com uma integralidade onde a pessoa se constitui numa rede de relações que envolvem o lugar onde ela nasce, as montanhas, os rios, a floresta, o deserto, todas as potências que envolvem a nossa experiência como seres humanos. 
Além do que é acrescentado de sentido da cultura, das classes de idade e gênero, tudo isso tem que ser posto em questão quando você está em contato com outra visão de mundo, outra cosmovisão. Onde a construção da pessoa é um edifício colaborativo entre a cultura em que surge, o lugar onde vive, as circunstâncias que são possibilitadas a essas famílias se deslocarem e viver, é nessa trajetória, é nesse caminho que se constitui, que uma pessoa se forma. No ocidente, persiste a ideia de que alguém nasce como que um evento somente biológico, que, sendo saudável e protegido, vai crescer saudável, aí precisa ser formada por uma instituição escola, que deve transformar em pessoas produtivas, ativas, integradas a uma sociedade regional, nacional, integrada ao mercado e ao mundo da produção. É verdade que as pessoas que não são desses povos originários, e que vieram pela diáspora ou para colonizar, vão buscar em sala de aula a formação desde cedo, no período da formação das crianças no ensino fundamental e ensino médio, dar complexidade ao pensamento, quando finalmente eles alcançam esse nirvana que é a universidade, um lugar de pensamento incrível. Quem inventou isso?

Mais do que pensar a presença dos índios na universidade, tomara que a presença de alguns pessoas desses povos originários possa implicar com os ambientes das universidades no Brasil, ao ponto de a ideia de universidade ser transformada por um pensamento crítico, acerca do que essa instituição privilegiada da sociedade ocidental elege como um lugar do pensamento culto, das ideias complexas e do planejamento que é devolvido, depois, para a sociedade como uma espécie de norma para a boa existência de uma comunidade civilizada, contemporânea e que reproduz o sistema capitalista do mundo do trabalho. Assim, por isso, as pequenas nações periféricas como Brasil, Argentina, Chile, os países da Ásia e da África, são avaliadas por quantas universidades esses lugares do mundo têm, mantêm e qual a performance que essas universidades desenvolvem no contexto global, quantos novos estudos, pesquisas, patentes e invenções esses centros de conhecimento publicam. Vocês não veem toda hora os rankings das universidades mais bacanas do mundo, quanto Nobel, quantas pesquisas, quantos prêmios eles ganharam?

Então, de certa maneira, nós podíamos pensar uma imagem dessas instituições como uma pirâmide. Na base dessa pirâmide estão as populações, as nações, os povos que historicamente foram colonizados e subjugados por aquelas nações que têm uma hegemonia e um controle sobre os processos globais de desenvolvimento, de configuração das tecnologias, dos modos de fazer e da própria ideia do que é progresso, desenvolvimento, os modelos. Então, se nós estamos num lugar que é periferia do mundo, nós devemos, criticamente, buscar referências que fortaleçam a nossa identidade nacional, sem diluir as nossas alteridades. Nós podemos todos nos entender como povo que compartilha essa identidade de povo brasileiro, mas nem por isso a gente precisa fazer desaparecer as nossas diversas alteridades, onde não só as identidades latentes devem ser reconhecidas e expressas, mas as subjetividades também, que alimentam o conhecimento, que elegem os saberes, possam ser também reconhecidas, elas não precisam ser respeitadas, mas elas precisam ser reconhecidas. 
Alguém pode imaginar que eu estou reivindicando que saberes extracurriculares, que os saberes da natureza, que os saberes de outros mundos sejam integrados ao sistema da universidade. Não é isso que eu estou reivindicando. O que eu estou, pelo menos, chamando a atenção, é que dentro desse sistema de cooptação do conhecimento, que as instituições da universidade consagram, que não haja uma atitude preconceituosa contra os saberes, que não tenha uma atitude reagente contra outros saberes, pois essa atitude reagente contra outros saberes denota, na verdade, um "ensimesmamento" e uma radical centralidade que só pode ser garantida pela força, que é o que alguns tiranos fazem, pois querem todo mundo num planeta, mas continuam legislando sobre como o resto do mundo vai funcionar. É isso o que acontece nas conferências sobre mudanças climáticas, onde Japão, Estados Unidos, China e Europa juntam meia dúzia de sujeitos e decidem que nós vamos continuar usando combustíveis fósseis, porque ainda tem muito petróleo e tem muito carro para vender por aí e que o resto se dane. Então, essa centralidade das economias do norte, que decide que nós somos apenas fornecedores de matéria prima, seja um rio, uma montanha ou o que está debaixo da terra, tem causado muitos danos para muitos povos em diferentes lugares do mundo, mas principalmente em regiões da América Latina, onde nós vivemos, onde nossas famílias pretendem continuar vivendo, porque a despeito de todas as negativas, a Terra é uma só, se a gente exaurir a possibilidade de suprimentos para uma vida boa aqui na Terra, nós não temos outro lugar para nos acolher.

Então eu não podia perder a oportunidade de falar com uma turma tão bacana como vocês, compartilhar com vocês um pouco da visão do que eu vislumbro como a presença indígena na universidade. A presença indígena só tem sentido pela diferença, ela não tem sentido pelo nivelamento, isso se vocês acharem que os indígenas que estarão na universidade, à exceção da sua cor, e os negros que prestarão a universidade não precisarão nada além de desprezar o seu black e ficar igualzinho a um outro na sua configuração, assim, esse nivelamento estético, esse nivelamento conceitual do que é a pessoa, digamos, de 'boa aparência' - o que, descaradamente, algumas empresas ainda têm coragem de incluir na sua classificação de seleção de emprego, para trabalho. De repente tem uma vaga para engenheiro, mas se você cultiva um corte de cabelo black power não serve: "você pode ser um ótimo engenheiro, mas, por favor, corte o cabelo, e você aí, você é um ótimo biólogo, mas caramba, você vem tocar maracá aqui no nosso laboratório, você quer conversar com as plantas? Então, você não, eu vou ficar com aquele outro carinha ali, ele não conversa com plantas, não toca maracá e não tem black power". Então, tem uma seleção, que não é aquela do Darwin, é outra. Tem uma seleção sobrenatural que decide quem de nós pode, quem de nós não serve para o ambiente do trabalho. Da mesma maneira que se é aplicada à natureza, é aplicada aos seres humanos, tem rios que podem morrer.

O que vocês acham de a gente matar o Mississipi? Tem rios que já foram escolhidos para morrer, o Rio Doce, por exemplo. Assim, o Xingu está na mira. Vamos fazer Belo Monte, vamos fazer qualquer coisa para mover a economia. O Tapajós está na mira também. Então, que seleção sobrenatural é essa que nós decidimos quais os saberes que valem, quais os que não valem? Qual 
o repertório que é eletivo para constituir uma comunidade bacana e qual repertório a gente deve apagar porque não interessa ao mercado? Parece que esses tais valores que orientam todo esse processo são exclusivamente o da grana. Se qualquer coisa dá grana, ela vai adiante, mesmo que seja droga, é por isso que a droga movimenta uma grana muito maior do que o PIB da maioria dos países periféricos que a gente conhece, e quem fatura com isso são exatamente aquelas nações ricas, bonitas e bacanas, porque além de distribuir armas e drogas para o mundo inteiro, elas elegem o que é bom e o que é ruim.

Então, despertar o senso crítico é tudo o que a gente pode fazer de melhor para a gente defender as nossas possibilidades, os nossos pontos de vistas, dos lugares onde nós vivemos como sujeitos coletivos, não como sujeitos individualistas, que está cada um buscando uma saída para si. Nós temos que pensar a possibilidade de um desenvolvimento que seja o desenvolvimento do ser humano integrado com possíveis desenvolvimentos de outros termos, inclusive da economia, mas hoje nós somos subjugados pela lógica da economia. Todos os outros campos que podíamos desenvolver como seres humanos são subjugados pela lógica da economia, tanto que a crise da economia justifica o golpe, justifica qualquer baixaria, porque nós estamos sem grana. "Desculpa aí, eu vou te atropelar porque estou sem grana". Então, em nome, descaradamente, de uma circunstância econômica muitas regiões do mundo são golpeadas nos seus direitos fundamentais, suspensos temporariamente, até que a economia volte a funcionar bem legalzinha, e aí a gente devolve o refém dos direitos humanos. Então, em alguns lugares do mundo, os direitos humanos foram como reféns, porque eles podem ser sequestrados em situação peculiar e devolvidos quando tudo volta à anormalidade normal. Eu espero que esse breve período de suspensão dos direitos da cidadania que vivemos em nosso país seja superado, e que as universidades cumpram seu papel fundamental de centros de debate, de crítica, de pensamento crítico sobre a nossa sociedade, que não fique fechado em si mesmo. Parabéns por esse pequeno gesto de conciliação que essa universidade está fazendo, e muito obrigado por vocês me ouvirem com tanta atenção. 